\title{
LETTER
}

\section{Vasopressin and terlipressin in adult vasodilatory shock}

\author{
Angelo Polito*1, Emilio Parisini², Zaccaria Ricci', Sergio Picardo and Djillali Annane ${ }^{3}$ \\ See related research by Serpa Neto et al., http://ccforum.com/content/16/4/R154
}

We have read with interest the study by Serpa Neto and colleagues showing that vasopressin use in vasodilatory shock is associated with reduced mortality [1]. However, we believe there are three aspects that need clarification.

In relation to the paper recently published by our group on the same topic, the authors correctly state that 'we only analyzed adult patients because pediatric shock has a much lower mortality that adult shock and this may "contaminate" the overall results' [1]. For the main analysis in our article, we computed data from six randomized trials exploring use of vasopressin/terlipressin only in adults [2]. Mortality in children was examined in a separate subgroup analysis.

Second, we intentionally excluded the paper from Argenziano and colleagues because this study examined the use of vasopressin in patients after cardiopulmonary bypass and ventricular assist device placement, a quite unique patient population with regards to the pathophysiology of shock [3]. Argenziano and colleagues' study was also carried out in a time of very different standards of intensive care (1997), compared with all other studies that were performed in the mid to late 2000s.

Moreover, the 'reduction in norepinephrine requirement' presented by the authors is not in conflict with our finding of a significant inverse relation between the vasopressin dose and the norepinephrine dose [2].

On a side note, we believe the authors' choice of using a fixed-effect model to compute a pooled estimate of the relative risk is questionable because it is based on the unlikely assumption that no statistical heterogeneity is present among the included studies.

\section{Authors' response}

Ary Serpa Neto and James A Russell

First of all we would like to thank Polito and colleagues for their interest, comments and criticisms.

Despite the unique type of population studied in the paper by Argenziano and colleagues [3], the definition of vasodilatory shock used by the authors was the same as that used in the other studies we analyzed (hypotension plus adequate cardiac output, measured as left ventricular assist device output). We also believe that the hallmarks of shock in these patients are the same as those in the other studies: hypotension, lactic acidosis, and profound vasodilatory hypotension unresponsive to catecholamines [4].

We agree that our findings of 'reduction in norepinephrine requirements' are not in conflict with the results of Polito and colleagues [2]. In our paper we did

*Correspondence: angelo.polito@opbg.net

'Department of Cardiology, Bambino Gesù Children's Hospital, Piazza S. Onofrio 4, 00165 Rome, Italy

Full list of author information is available at the end of the article not state the contrary, we only stated that we analyzed this variable in another way - using the standardized mean difference, which is a methodology different from meta-regression to analyze the reduction in norepinephrine requirements [1].

Finally, we used the fixed-effect model in the pooled estimate of the risk ratio of mortality because we did not find any signs of statistical heterogeneity, as can see by the low $I^{2}$ values ( $0 \%$ in all comparisons) and by the high $P$ values (always above 0.50 ). We believe that the choice of which test to use cannot be made based only on the basis of the heterogeneity test. Furthermore, all studies that we evaluated and included in our review share a common effect size, which makes the use of the fixedeffect model appropriate.

\section{Competing interests}

The authors declare that they have no competing interests.

\section{Author details}

'Department of Cardiology, Bambino Gesù Children's Hospital, Piazza S. Onofrio 4, 00165 Rome, Italy. ${ }^{2}$ Center for Nano Science and Technology @ POLIMI, Istituto Italiano di Tecnologia, Via G. Pascoli 70/3, Milano 20133, Italy. 
${ }^{3}$ Critical Care Department, Hôpital Raymond Poincare (Assistance PubliqueHôpitaux de Paris), University of Versailles, Garches 92380, France.

Published: 28 December 2012

\section{References}

1. Serpa Neto A, Nassar Junior AP, Cardoso SO, Manettta JA, Pereira VG, Esposito DC, Damasceno MC, Russell JA: Vasopressin and terlipressin in adult vasodilatory shock: a systematic review and meta-analysis of nine randomized controlled trials. Crit Care 2012, 16:R154.

2. Polito A, Parisini E, Ricci Z, Picardo S, Annane D: Vasopressin for treatment of vasodilatory shock: an ESICM systematic review and meta-analysis. Intensive Care Med 2012, 38:9-19.
3. Argenziano M, Choudhri AF, Oz MC, Rose EA, Smith CR, Landry DW: A prospective randomized trial of arginine vasopressin in the treatment of vasodilatory shock after left ventricular assist device placement. Circulation 1997, 96(9 Suppl):II-286-290.

4. Morales DL, Gregg D, Helman DN, Williams MR, Naka Y, Landry DW, Oz MC: Arginine vasopressin in the treatment of 50 patients with postcardiotomy vasodilatory shock. Ann Thorac Surg 2000, 69:102-106.

doi:10.1186/cc11887

Cite this article as: Polito A, et al:. Vasopressin and terlipressin in adult vasodilatory shock. Critical Care 2012, 16:470. 